\title{
El uso del cómic en el aula de Francés como Lengua Extranjera (FLE)
}

The use of comics in French as a Foreign Language (FFL) classes

\author{
Ana Belén Soto \\ e-mail: anabelen.soto@uam.es \\ Universidad Autónoma de Madrid. España
}

\begin{abstract}
Resumen
Inmersos en la era de la imagen y de las tecnologías, la didáctica de las lenguas extranjeras se encuentra ante un escenario que posibilita la renovación de la enseñanza tradicional en el aula y fomenta la motivación en el proceso de enseñanza y aprendizaje. Por ello, en el artículo aquí presentado reflexionaremos sobre el uso del cómic como herramienta pedagógica en el aula de FLE (Francés como Lengua Extranjera) a partir de una selección. El cómic representa una forma de expresión literaria que imbrica el texto y la imagen y esto lo convierte en un atractivo recurso pedagógico que permite fomentar los hábitos de lectura del alumnado. El cómic, además, presenta un gran potencial en la didáctica de las lenguas extranjeras, ya que no sólo nos permite profundizar en la experiencia lingüística, sino que además posibilita al docente un acercamiento a diferentes contextos educativos tanto comunicativos como socioculturales. Huelga decir que el francés es lengua vehicular en los más de 80 países que conforman la Francofonía y que las producciones literarias en este ámbito representarán el abanico de acentos, representaciones socioculturales y contextos históricos de esta realidad lingüística transnacional, plurilingüe e intercultural.
\end{abstract}

Palabras clave: recursos pedagógicos; Francés como Lengua Extranjera (FLE); cómic; literatura; francofonía

\section{Abstract}

Immersed as we are in the era of image and technologies, the teaching of foreign languages is now in a scenario which enables the renewal of traditional teaching in the classroom and encourages motivation in the process of teaching and learning. That is why in the article we present here we reflect on the use of the comic as an educational tool in the FFL (French as a Foreign Language) classroom based on a selection. The comic, a literary expression where image and text are interwoven, makes an attractive educational tool, promoting students' reading habits. In addition, it presents a high potential in the teaching of foreign languages, as it not only allows us to deepen the linguistic experience, but also enables the teacher to approach different communicative and socio-cultural educational contexts. It goes without saying that French is the working language in the over 80 countries which make up the Francophonie, and that the literary productions in that sphere of activity will represent the scope of accents, socio-cultural representations and historical contexts of that transnational, multilingual and intercultural linguistic reality.

Keywords: teaching resources; French as a Foreign Language (FLE); comic; literature; francophony

Recibido / Received: 04-02-2019

Aceptado / Accepted: 02-04-2019

Publicación en linea / Published online: 15-05-2019

Cómo referenciar este artículo / How to reference this article:

Soto, A. B. (2019). El uso del cómic en el aula de FLE. Tendencias Pedagógicas, 34, pp. 139-152. doi: $10.15366 /$ tp2019.34.011 


\title{
1. Introducción
}

En este artículo queremos presentar una reflexión que gira en torno al uso del cómic como recurso pedagógico en el aula para estimular la competencia comunicativa en el proceso de aprendizaje del francés como lengua extranjera (FLE). Huelga decir que enseñar una lengua extranjera implica elaborar una serie de herramientas pedagógicas que permitan profundizar en la experiencia lingǘstica en el contexto histórico, social y cultural de la lengua aprendida. El Marco común europeo de referencia para las lenguas (2002), de hecho, describe así el uso de la lengua:

\begin{abstract}
«El uso de la lengua -que incluye el aprendizaje- comprende las acciones que realizan las personas que, como individuos y como agentes sociales, desarrollan una serie de competencias, tanto generales como competencias comunicativas lingüísticas, en particular. Las personas utilizan las competencias que se encuentran a su disposición en distintos contextos y bajo distintas condiciones y restricciones, con el fin de realizar actividades de la lengua que conllevan procesos para producir y recibir textos relacionados con temas en ámbitos específicos, poniendo en juego las estrategias que parecen más apropiadas para llevar a cabo las tareas que han de realizar. El control que de estas acciones tienen los participantes produce el refuerzo o la modificación de sus competencias» (MCER, 2002, p. 9).
\end{abstract}

Estamos, por consiguiente, ante un enfoque orientado a la acción.

De tal manera que el profesor tiene la responsabilidad de propiciar un espacio de aprendizaje global en el que los alumnos puedan desarrollar actitudes y destrezas interculturales en lengua extranjera. El docente, en efecto, representa la base que guía, favorece y motiva el proceso de enseñanza-aprendizaje y, por ello, debe animar a conocer la lengua, el territorio geográfico en el que se utiliza esa lengua, las características socioculturales ligados a dichos contextos; así como el lenguaje gestual, las convenciones sociales y las costumbres, en la lengua extranjera que imparte. Además, es importante subrayar que el MCER (2002) reflexiona no sólo sobre una escala y un orden comunes en materia de contenidos contenidos, sino también sobre el papel que desempeñan los profesores y los alumnos, sobre el papel otorgado a los medios audiovisuales y a las herramientas textuales y sobre las tareas y las actividades que pueden desarrollarse desde un punto de vista didáctico. En este sentido debemos poner de relieve la clasificación de textos que presenta el MCER (2002, p. 93), pues en ella se incluye el estudio de las tiras cómicas, lo que implica un reconocimiento de este recurso pedagógico con el objetivo de diversificar los documentos auténticos utilizables en aula.

El uso del cómic en el aula resulta especialmente interesante por los beneficios que este género presenta en el ámbito de la enseñanza de las lenguas extranjeras, pues se puede trabajar tanto desde un punto de vista artístico-literario como sociocultural y educativo. Esta herramienta de lectura ha vivido en las últimas décadas un crecimiento significativo y no sólo se diversifica desde un punto de vista temático, sino que además se transforma siguiendo el desarrollo sociocultural y tecnológico. En efecto, en la actualidad encontramos adaptaciones de novelas como $\dot{A}$ la recherche du temps perdu de Proust ${ }^{1}$, adaptaciones del cómic en la gran pantalla como Persépolis ${ }^{2}$ e, incluso, adaptaciones del cómic

\footnotetext{
${ }^{1}$ La novela fue escrita entre 1906 y 1922 y fue publicada entre 1913 y 1927 en siete tomos, de los cuales tres fueron publicaciones póstumas. Numerosas han sido las adaptaciones que se han hecho de esta novela en el ámbito audiovisual, nosotros debemos destacar la adaptación en cómic presentada por Stéphane Heuet y publicada en 6 volúmenes de 1998 a 2013.

2 Persépolis es una película de animación basada en la novela gráfica del mismo nombre creada por Marjane Satrapi. Dirigida por Vincent Paronnaud y producida por Xavier Rigault y Marc-Antoine Robert, ésta obtuvo una candidatura a la Palma de Oro y consiguió el Premio del jurado en el Festival de Cannes de 2007.
} 
en el universo digital ${ }^{3}$. En este sentido, podemos situar el universo cómic en un contexto en auge que presenta una variedad de recursos disponibles interesante para su explotación en el aula de FLE.

Gracias a la imbricación del texto y de la imagen, el cómic nos permite trabajar una multiplicidad de aspectos de manera simultánea y transversal. Esto representa una manera de diversificar los acercamientos al aprendizaje de una lengua extranjera. En el caso del francés, además, debemos cuestionarnos sobre la relevancia y la pertinencia del uso del cómic en el aula no sólo como herramienta pedagógica, sino también como fuente de transmisión cultural, ya que

«depuis plus d'une quinzaine d'années, la bande dessinée connait en France un nouvel âge d'or. Le secteur s'est imposé comme l'un des plus créatifs entre 1991 et 2016. Le nombre d'ouvrages publiés est passé de 1.137 publications annuelles, en 2000, à 5.305 en 2016, chiffre qui témoigne d'un dynamisme éditorial, avec plusieurs éditeurs inventifs et défricheurs. La part des prêts en bibliothèque constituait, en 2016, $27 \%$ du nombre total, arrivant devant les prêts de littérature de fiction adulte qui s'élevait à $24 \%$. Plusieurs grands éditeurs investissent dans la BD. Gallimard a, par exemple, créé en 2006 un département bande dessinée» (Lungheretti, 2017: www.lemonde.fr).

Francia, no obstante, no es el único país al que hacemos referencia cuando transmitimos la lengua francesa, pues muchos son los países pertenecientes al ámbito de la Francofonía. De tal manera que el uso del cómic en el aula también nos invita a hablar de lugares como el Centro Belga de la Bande Dessinée, ya que, con sus más de 700 autores de cómic, Bélgica es el país que tiene una mayor densidad de creadores por kilómetro cuadrado. Asimismo, podemos identificar una cartografía de festivales del cómic francófono que nos lleva desde Suiza -Lausanne, Sierre, etc.- hasta Canadá -Québec, Montréal, etc.-, pasando por Marruecos -Casablanca, Fez, etc.- entre otros países. Por último, debemos subrayar que en el panorama historietista, al igual que ocurre en el ámbito de la novela o de la poesía, también encontramos escritores extranjeros que deciden utilizar la lengua francesa como vehículo de expresión literaria, tal es el caso de la polaca Marzena Sowa o de la iraní Marjane Satrapi. Se trata, por consiguiente, de un género literario que atraviesa las fronteras geográficas del hexágono y que nos permite observar un amplio abanico sociocultural cuyo nexo de unión es la lengua francesa.

Por ello, nos proponemos esbozar brevemente en el presente artículo un abanico de posibilidades de explotación pedagógica a través del uso de algunos de los cómics que ofrece el mercado. Nuestra propuesta no pretende ser exhaustiva, sino que tiene como objetivo el despertar el interés que esta herramienta ofrece en el ámbito que nos ocupa. Para ello, y con el objetivo de contextualizar el tema, en un primer momento realizaremos un recorrido sobre los orígenes del cómic. Seguidamente, sintetizaremos la presencia del cómic en el ámbito educativo, haciendo especial hincapié en los escenarios educativos que se presentan en España y en Francia. Por último, presentaremos una serie de elementos de reflexión para el uso del cómic como herramienta pedagógica en el aula de FLE a través de las obras seleccionadas.

\section{Orígenes y contexto}

«El origen del cómic está estrechamente vinculado a las características económicas, sociales y culturales de la sociedad en la que se origina. El cómic tal como lo conocemos hoy día es fruto de varios siglos de experimentación. Como forma de representación debe asociárselo a la cultura de masas. Un cómic -dice R. Gubern- producido en el taller del dibujante, pero no multiplicado mediante el proceso de multiplicación, no es todavía un verdadero cómic, del mismo modo que el dibujo sobre la piedra litográfica no es aún el grabado litográfico. La lámina del dibujante es

\footnotetext{
${ }^{3}$ En el ámbito digital hablamos de webcómic para designar principalmente a los cómics creados de manera digital (también llamados e-comic), aunque existen muchos webcómics que también son publicados en formato papel. El primer webcómic, Where the Buffalos Roam (1992) de Hans Bjordhal, fue creado a partir de unas tiras en papel que posteriormente digitalizó. En la actualidad muchas son las aplicaciones que facilitan la creación digital y, por ende, la incorporación de elementos audiovisuales, adaptando así su producción al mercado editorial y al público emergente.
} 
sólo un proyecto de comunicación de masas, es una matriz quirográfica y artesanal que precede al nacimiento del cómic por obra de las tecnologías reproductoras. El cómic [...] [es], por consiguiente, un producto industrial, independientemente de su valoración estética o semiótica» (Aparici, 1991, p. 18).

Desde esta perspectiva podemos observar cómo se asocia la aparición del cómic a la cultura de masas y, por ende, a los nuevos hábitos de consumo que surgieron con la industrialización en materia de entretenimiento. Asimismo, debemos señalar la evolución de la imprenta como punto de partida de la historia del cómic para especialistas como David Kunzle o el editor de historieta español Pedro Porcel (Casas, 2015: 18). En este contexto, Roberto Aparici (1992) considera al caricaturista inglés James Gillray como a uno de los primeros precursores del cómic por su publicación en prensa de una litografía satírica de Napoleón Bonaparte hacia 1800.

No existe, sin embargo, unanimidad en cuanto a los orígenes del cómic. Para el especialista Federico López Socasau:

«tal vez los bocadillos de Yellow Kid sean la diferencia más notable que encontraron los once expertos reunidos en el Salón de Lucca de 1989, entre esta serie y las creaciones anteriores, de autores del siglo XIX, como Töpffer o Buch, para decidir que el cómic había nacido en 1896. Sin embargo, ésta no es la única interpretación sobre su origen. En octubre de 1996 se celebró un Congreso Internacional, de estudiosos e historiadores del cómic en el Centre Belge de la Bande dessinée, y en él se llegó a la conclusión de que el cómic nació en Europa en el siglo XIX, entre 1865 y 1890.» (1998, p. 10).

Muchos son los investigadores que compartirán esta idea como origen de lo que hoy día consideramos como cómic, ya que Yellow Kid (publicada entre 1895-1898) presenta una secuencia de imágenes consecutivas que articulan el relato en torno a un personaje estable que prolonga el hilo argumentativo de la historia, lo que representa un rasgo distintivo a la vez que definitorio del cómic.

Gombrich, sin embargo, sostendrá que «corresponde al humorista y dibujante ginebrino Rodolphe Töpffer el haber inventado la historieta dibujada» (citado en Aparici, 1992, p. 19). Josefina Prado Aragonés (1995), por su parte, atribuye su aparición al caricaturista alemán Wilhelm Buch (1965) y su afianzamiento como género a los suplementos dominicales de los periódicos norteamericanos. Otros, como Scott McCloud (2005) considerarán los libros ilustrados de los aztecas y algunas pinturas egipcias como precursores del género, argumentando que el cómic es un conjunto de «ilustraciones y otro tipo de imágenes yuxtapuestas en secuencia deliberada, con el propósito de transmitir información y obtener una respuesta estética del lector» (McCloud, 2005, p. 9). Se trata de una perspectiva que genera discrepancias y que es analizada en ocasiones como una manera de ennoblecer el origen histórico de los cómics (Gubern, 1974; citado por Gómez Salamanca, 2013).

Por otra parte, nos resulta especialmente interesante observar cómo la forma de denominar este concepto de expresión literaria tampoco es unánime. De tal manera que si bien en castellano utilizamos «cómic» por proximidad al anglicismo, «tebeo» en referencia al éxito que tuvo la revista $\mathrm{TBO}^{5} \mathrm{O}$ «historieta» poniendo el énfasis sobre el aspecto narrativo de la obra, no todas las lenguas adoptan la misma perspectiva para expresar esta realidad literaria:

\footnotetext{
${ }^{4}$ Yellow Kid es un personaje que apareció por primera vez el 5 de mayo de 1895. «En un principio este pequeño oriental vestía de azul, pero posteriormente, a partir del 5 de febrero de 1896, lo hizo con un camisón amarillo [...]. En un principio los textos iban escritos dentro del camisón, que a la vez servía de bocadillo» (López Socasau, 1998, pp. 77-78).

${ }^{5}$ Fundada en 1917, «según cuenta Luis Conde [...], TBO debe su nombre a las iniciales de su primer editor, el empresario mallorquín Tomás Bauçá Oliver. [...] La importancia de esta publicación para el público infantil hizo que todos comenzaran a denominar tebeos a las publicaciones periódicas de historietas. En 1968 este término sería admitido por la Real Academia Española para referiste a las publicaciones similares » (López Socasau, 1998, pp. 91-92).
} 
«en chino, lianbuanbua significa, literalmente, imágenes encadenadas; en francés bande dessinée, o B.D., significa tira dibujada, haciendo referencia a sus orígenes; en italiano fumetto (en plural, fumetti) hace referencia a los bocadillos en los que se expresan los personajes, haciendo alusión metafórica a su apariencia de "humitos"; [...] en portugués, quadrinhos hace referencia a las viñetas» (López Socasau, 1998, p. 11).

Esta multiplicidad de perspectivas también se refleja en su definición terminológica: el influyente historietista estadounidense William Erwin Eisner (1966) pone de relieve el carácter secuencial del cómic; Scott McCloud, autor, ensayista y teórico de cómics, se centra la superposición de imágenes con el propósito de transmitir información y obtener una respuesta estética del lector; etc. De ahí que, con el objetivo de presentar una definición que sintetice la multiplicidad de perspectivas a este respecto, podamos citar a los especialistas Arango Johnson, Gómez Salazar y Gómez Hernández:

\begin{abstract}
«mensaje secuencial diacrónico, narrativo o descriptivo, en el que predomina la acción; construido por medio de viñetas y otros signos verbo-icónicos, que siguen una línea de indicación y conforman códigos sistematizados hacia un sentido determinado. Es un producto cultural creado para entretener, concebido como medio masivo de comunicación. Desde el punto de vista semiótico el cómic connota, y conduce a un sistema icónico, y denota la presencia de un sistema político y social, que expresa su pedagogía.» (2009, p. 21).
\end{abstract}

No obstante, e independientemente de las controversias generadas en torno a las denominaciones y a las definiciones que permiten enfocar los orígenes del cómic desde diferentes perspectivas, podemos afirmar que la prensa y las tecnologías desempeñaron un papel esencial en la producción historietística. En efecto, hacia finales del siglo XIX los periódicos, buscando multiplicar su número de lectores, recurrían a la publicación de viñetas. De hecho, tal y como constata Aparici (1992: 20), gracias a la modernización de los sistemas de impresión en los periódicos estadounidenses, a partir de 1893 los suplementos dominicales presentarían una página en color y, en 1895, aparecerá en el New York World, una viñeta a color del dibujante Richard F. Outcault que sentará una de las bases para la evolución historietística hasta nuestros días.

El mundo del cómic constituye hoy una industria muy desarrollada que abarca en la actualidad una multiplicidad de temáticas y presenta ilustraciones de alta calidad. También constatamos que se aleja de esos orígenes ligados al entretenimiento de aspecto gracioso y presenta temáticas para todos los públicos. De ahí que se trate de un ámbito que ha despertado el interés de muchos estudiosos; por ello, en los últimos años hemos visto proliferar una serie de artículos tanto sobre la pertinencia como sobre la introducción del cómic como elemento pedagógico, pasando por la historia y el género al que pertenecen, tal y como señala Buron-Brun (2016, p. 15).

Por otra parte, resulta imprescindible señalar que el universo del cómic mueve una cantidad considerable de lectores y que presenta un escenario proclive a la proliferación de eventos que generan un gran impacto económico. Pensemos en el Festival de Angulema, por ejemplo, que, creado en 1974, acoge en la actualidad cerca de 6.000 profesionales del cómic a nivel intencional y a más de 220.000 visitantes cada año, tal y como se recoge en la web del festival. También debemos referirnos a la Convención Internacional de Cómic de San Diego, ya que es considerada como «la convención más grande en su tipo en los Estados Unidos, y la cuarta más grande del mundo, sólo superada por la Comiste en Japón [...], el Festival Internacional de [...] Angulema en Francia y la Lucca Comics and Games en Italia» (Casas, 2015, p. 50). De hecho, el interés que despierta el universo del cómic ha creado un mercado para los coleccionistas que llegan a pagar precios desorbitados por un ejemplar. Tanto es así que, en una subasta de 2012 se llegó a pagar hasta $850.000 \$$ por el primer número de Batman, un precio considerable, que Casas (2015, p. 65) caracteriza como precio récord a la vez que recuerda que estamos hablando de un ejemplar que apareció en los años 40 con un coste de diez céntimos. En el ámbito europeo debemos destacar el mercado francófono pues, tal y como señala López Socasau (1998, p. 80), el mercado consagrado al cómic en Francia y Bélgica se caracteriza por ser prolífero y activo. De hecho, en París, por ejemplo, se celebran subastas periódicas en lugares como el Hôtel Drouot-Richelieu, situado en el IX Distrito de París. Huelga decir que en la actualidad, existen numerosas páginas de subastas en Internet que permiten participar en la compra-venta desde cualquier punto del mundo. En España también se ha despertado el interés coleccionista y muchos son los lugares donde podemos encontrar tesoros, como los llama el especialista anteriormente citado. Según su criterio, «los lugares idóneos para buscadores de tesoros en España [se encuentran] entorno del 
Mercado de San Antonio en Barcelona, el Rastro de Madrid y, por supuesto, librerías de viejo y especializadas» (López Socasau, 1998, p. 80).

De tal manera que podemos afirmar que nos encontramos ante un fenómeno de interés emergente que aúna autores, editores, críticos, agentes editoriales, coleccionistas, lectores y curiosos. Por ello, tratar el análisis de un cómic en el aula se convierte en un tema de actualidad que no sólo permite utilizar un documento auténtico, sino que además presenta un escenario pedagógico atractivo para la adquisición de conocimientos y competencias comunicativas lingüísticas y socioculturales a la vez que potencia el aprendizaje transversal.

\section{El uso del cómic como recurso educativo}

«Notre monde contemporain est à l'évidence caractérisé par la nature pluriforme des sociétés du point de vue du langage et de la culture, par l'évolution et la prolifération technologique à un rythme rapide et continu, la souveraineté des médias, de l'image et de l'écran, ainsi que par la coexistence de plusieurs modes sémiotiques dans les productions culturelles. Dans ce cadre, la notion de littératie revêt un sens nouveau puisque les compétences de l'homme lettré se transforment constamment. Ces constatations impliquent un nouveau rôle pour l'école. Il s'agit de conduire les élèves à construire des compétences leur permettant de recevoir et de décoder cette nouvelle réalité, ainsi que d'y participer efficacement» (Missiou, 2012, p. 79).

La evolución tecnológica, en efecto, abarca todos los ámbitos de la sociedad y propicia una renovación formal de las estructuras tradicionalmente establecidas. En el ámbito de la educación resulta tanto más importante cuanto que los docentes debemos contribuir a la construcción de una ciudadanía formada y preparada capaz de afrontar los retos del mañana. En la actualidad la educación tiene el deber de contribuir a la creación de ciudadanos mediáticos en igualdad de condiciones, y para ello, tal y como afirman especialistas como Manuel Barrero (2002, p. 5), «hoy, más que nunca, en estos días en los que los espacios virtuales proliferan, es importante educar en la contemplación e interpretación de imágenes».

Se trata, por consiguiente, de un aspecto a tener en cuenta en la experiencia docente. Huelga decir que la didáctica es el arte de enseñar, pero también de pensar en las herramientas pedagógicas más apropiadas para transmitir y adquirir los conocimientos. En este sentido, los instrumentos tecnológicos y en concreto el papel de la imagen son un aspecto cada vez más importante que tener en cuenta en la práctica docente. Ya, a finales de los ochenta, los especialistas Mauro Rollán Méndez y Eladio Sastre Zarzuela (1986, p. 11) hablaban del uso de la cámara fotográfica o de la calculadora, novedades tecnológicas del momento, como «instrumentos didácticos tan aprovechables como el lápiz o la goma de borran». En la actualidad, con la evolución tecnológica tenemos a nuestra disposición la inmensa mayoría de las novedades del pasado cercano desde nuestros dispositivos móviles. El teléfono ya no sólo sirve para realizar comunicaciones a distancia, sino que además se ha convertido en un pequeño ordenador que nos acompaña en todo momento y que nos permite realizar, editar y almacenar documentos audiovisuales de diferentes índoles; que nos lleva por el camino más corto de un punto a otro, ya sea andando, en transporte público o en coche; que nos permite realizar pagos e incluso operar desde cajeros y gestionar las cuentas bancarias. Y, seguramente, estos avances tecnológicos sean antiguallas dentro de veinte años, puesto que dentro de las últimas novedades que se presentaron en el Mobile World Congress de 2018 se habló de la creación de cámaras que nos ayudarán a contar las calorías del plato que nos vamos a comer o que vamos a fotografiar para subirlo a Instagram e incluso de aplicaciones que escanearán las caras para crear emojis ${ }^{6}$. De tal manera que podemos constatar cómo las tecnologías contribuyen a la construcción de sociedades en las que las imágenes adquieren un papel cada vez más protagonista.

En este sentido, podemos establecer un punto de encuentro entre la lectura de un cómic y nuestro día a día: el uso de la imagen. Este nexo de unión supone una primera ventaja para el uso de este

\footnotetext{
${ }^{6}$ Para más información léase, por ejemplo, el artículo «Móviles listos, móviles tontos... y otras cinco lecciones del Mobile World Congress», publicado el 27 de febrero de 2018 en El Mundo.
} 
recurso desde un punto de vista pedagógico. Motivar a la lectura resulta, además, un aspecto especialmente relevante en España, ya que según las encuestas nos situamos por debajo de la media europea en términos de hábitos lectores. De hecho, según el Barómetro de Hábitos de Lectura y Compra de Libros de 2017 el porcentaje de lectores de libros en España mayores de 14 años es de un 65,8 \% de la población -frente al $70 \%$ de la media europea-. Existe, según este estudio, un 35,1 \% de la población que no lee porque no le gusta o porque no le interesa. Por ello, con el objetivo de reducir esa brecha, consideramos importante acercar el mundo del cómic a los diferentes públicos lectores y legitimar la presencia que adquiere en el ámbito educativo.

Asimismo, debemos señalar el valor icónico-verbal que posee el cómic, ya que ha sido valorado muy positivamente como soporte didáctico por diferentes especialistas. Para algunos especialistas como Rollán Méndez, Sastre Zarzuela (1986, p. 11), la imbricación del texto y de la imagen supone una ventaja frente a la enseñanza puramente verbalista y la exclusivamente icónica, ya que supone una síntesis equilibrada de ambas con el objetivo de enriquecer el proceso de enseñanza-aprendizaje. Otros, afirman que:

«desde el punto de vista del diseño de métodos de enseñanza-aprendizaje con herramientas gráficas de este tipo, hemos de destacar que la necesidad de interpretación de la imagen exigida por la lectura del cómic permite formular planteamientos construccionistas que se alejan de la tradicional clase magistral y que hacen del alumnado el verdadero protagonista de su proceso formativo. Mientras, el profesor adopta el rol de guía fundamental y facilitador de conocimiento» (Peña Acuña, 2014, p. 480).

Para otros especialistas, la labor didáctica del cómic no representa un hecho novedoso; de ahí que, basándose en las aleluyas como precursores de este género literario, especialistas como Peña Acuña (2014, p. 469) recuerden el impacto positivo que tuvo este tipo de publicaciones desde un punto de vista pedagógigo entre los inmigrantes no angloparlantes estadounidenses, quienes aprovecharon la sencillez de su lenguaje icónico-literario para acercarse a la lengua inglesa. En este sentido, aunque desde otra perspectiva, debemos destacar el método de lectura Boule et Bill (1990), creado en Francia para animar el aprendizaje de la lecto-escritura desde la perspectiva historietística. Por ello, podemos constatar que el cómic representa una herramienta pedagógica que ofrece un escenario beneficioso en el ámbito educativo.

En España, tal y como señalaba el especialista Manuel Barrero en su conferencia impartida sobre narrativa gráfica,:

«durante los años 70 se vivió en España el eco de la legitimación del medio por parte de los semióticos argentinos e italianos y por parte de los creadores y editores americanos y franceses, y si bien se vio reforzada la actitud de los pedagogos y de algunas instituciones de usar la historieta en el llamado boom en España (un poco a remolque de la apertura de miras y la transición política que vivíamos), lo cierto es que actualmente no se tiene tanto en cuenta la historieta como herramienta de aprendizaje. Como no se tiene muy en cuenta en la Cultura, en general.» (2002, p. 2)

Javier Ortiz (2009, p. 2) corrobora esta opinión y apunta que «el desvanecimiento de ese período de boom del cómic en la década de los 90 arrastró consigo su utilización como recurso didáctico, disminuyendo considerablemente su aparición y su uso en los libros de texto». Una postura que no es del todo compartida por el profesor López Socasau, quien pone de relieve la voluntad de acercamiento académico hacia el ámbito del cómic cuando señala en su reflexión sobre didáctica y cómic que:

«lo más interesante es el intento de acercar a la escuela la realización de cómics, bien organizando talleres en los que los alumnos pueden analizar las producciones más interesantes y realizar sus propias historietas emulando a los grandes creadores, bien considerando el estudio y análisis del cómic como un contenido más del programa de Lengua» (1998, p. 80).

Así, podemos observar visiones más o menos optimistas de un escenario educativo en el que constatamos discrepancias en cuanto al uso de este género literario. 
En el caso de Francia y de los países pertenecientes al ámbito de la Francofonía debemos hacer constar, por una parte, la importancia que adquiere la cultura historietística como verdadero fenómeno de civilización (Morlat y Momimoto, citado en Paré, 2016, p. 194) y, por otra, las políticas educativas francesas. Recordemos que, tal y como señalan las especialistas Paré y Soto Pallarés (2017, p. 141), desde la revolución de Mayo del 68 «Francia es un país que consideramos como precursor en Europa en lo que concierne la introducción del cómic en el currículo escolar». Para ello, muchas fueron las políticas educativas que apoyaron el uso del cómic como recurso educativo. En este sentido, debemos poner de relieve las iniciativas de Jack Lang, Ministro de Cultura de Francia de 1988 a 1992, pues representan un impulso importante para la visibilidad y el reconocimiento del uso del cómic en las aulas. En 1983 el Ministro afirma: «langage, moyen de communication, mode d'expression artistique, reflet immédiat d'une société, la bande dessinée est aujourd'hui reconnue comme activité créatrice à part entière qui est prise en compte comme telle par le Ministère de la Culture » (citado en Aulanier, 2013, p. 7). Un discurso que se convierte en el preámbulo de un proyecto de enseñanza que se concretiza desde 1987

«y se oficializa en los programas escolares en 1996 para el Collège, en 2001 para el Lycée y en 2002 para la Educación Primaria. [...] Además, es interesante señalar también que el año 2008 marca la oficialización de la asignatura Historia de las artes, nueva enseñanza obligatoria de carácter interdisciplinar que comprendía contenidos de lengua francesa, historia y artes plásticas. En dicha asignatura, el cómic está clasificado como "arte visual". La entrada del cómic en los programas escolares franceses significó el reconocimiento oficial de su importancia en el ámbito educativo» (Paré y Soto Pallarés, 2017, p. 137).

Se trata de un marco ministerial que permite institucionalizar la lectura de la imagen como tarea normalizada, a la vez que representa una iniciativa que refleja el interés por el cómic en el ámbito francófono ${ }^{7}$. De tal manera que el cómic, como recurso en el aula de FLE, se convierte a efectos normativos en una valiosa herramienta pedagógica de transmisión sociocultural e histórico-lingüística.

En este contexto, resulta especialmente interesante citar algunas de las funciones más relevantes de esta forma de expresión literaria en el ámbito docente. Para Manuel Barrero (2002), basándose en la experiencia docente de Óscar Díaz (1990), cuatro son las funciones pedagógicas principales del cómic: el estímulo de la creatividad, el fomento del aprendizaje, la alfabetización en el lenguaje icónico y su papel como ventana abierta hacia el mundo. Se trata de una visión compartida por otros autores como Javier Ortiz (2009) quienes desarrollan esas funciones principales y ponen de relieve, entre otras muchas ventajas, la idoneidad del uso del cómic como recurso en la didáctica de las lenguas extranjeras. De hecho, tal y como señala Paré:

«en didactique des langues et des cultures, la bande dessinée constitue un support de choix, comme en témoigne aujourd'hui sa très large présence dans les manuels d'enseignement. Son entrée en classe de langue date des années soixante-dix, lorsque s'élabore l'approche communicative et que le matériel pédagogique s'élargit aux supports pouvant relever de différents codes: scriptural, iconique, oral ou audiovisuel. Il s'agit alors de mettre l'apprenant au contact direct de la langue cible, tout en conciliant cet apprentissage avec celui de la civilisation. La $\mathrm{BD}$ constitue à cet égard un excellent exemple de « document authentique » élaboré «à des fins de communication réelle », tel que le définit Jean-Pierre Cuq». (2016, pp. 186-187)

El cómic, en efecto, se basa en el uso de códigos conocidos, como pueden ser los estereotipos o las expresiones gestuales, con el objetivo de comunicar una información concreta a través de unos estándares estéticos establecidos tales como el uso de viñetas y bocadillos o el juego con los diferentes planos con el objetivo de transmitir tal o cual cosa. En este sentido, desde el punto de vista de la didáctica de la enseñanza de las lenguas extranjeras, conviene señalar la heterogeneidad de contenidos -fonético, fonológico, lingüísticos, gramaticales, léxico-semánticos, culturales, etc.- que permite trabajar en el aula y su facultad para favorecer el trabajo tanto desde un enfoque individual como cooperativo en función de las actividades propuestas.

7 Véanse, por ejemplo, los resultados de los diferentes sondeos realizados en torno a los hábitos de lectura. 


\section{Posibilidades pedagógicas en el aula de FLE}

Los métodos de enseñanza de las lenguas extranjeras han evolucionado considerablemente desde el método tradicional, donde lo prioritario era el dominio de la gramática. Además de respetar los marcos institucionales a nivel nacional, en la enseñanza del FLE es recomendable conocer las pautas estipuladas por el Marco común europeo de referencia para las lenguas (2002) y por el recientemente publicado Cadre européen commun de référence pour les langues: apprendre, enseigner, évaluer. Volume complémentaire avec de nowveaux descripteurs (2018), dos documentos de referencia que pretenden establecer unos criterios comunes para enseñanza de las lenguas extranjeras en el marco europeo. En este sentido debemos poner de relieve que el MCER aboga por una metodología enfocada en la acción que trata de enseñar a los alumnos no sólo a comunicar, sino también a adquirir los aspectos socioculturales ligados al aprendizaje lingüístico. De ahí que podamos afirmar que el cómic presenta un recurso didáctico privilegiado en la media en la que recrea situaciones de comunicación y permite introducir de manera simultánea estructuras lingüísticas, léxico y aspectos socioculturales.

En este sentido, el docente que pretenda utilizar el enfoque orientado a la acción como base del proceso de enseñanza-aprendizaje necesitará definir una serie de $\operatorname{tareas}^{8} \mathrm{y}$ actividades ${ }^{9}$ que presenten un escenario pedagógico adecuado para los aspectos concretos que desee tratar. En este estado de la reflexión queríamos recordar que desde el presente artículo no pretendemos presentar, no obstante, una secuencia pedagógica de todos y cada uno de los cómics que exponemos a continuación, sino que se trata de reflexionar sobre las diferentes posibilidades que estos ofrecen para que los lectores puedan adaptar las diferentes propuestas a la metodología que se pretenda utilizar. Consideramos, sin embargo, que sería oportuno que, con el objetivo de crear una secuencia pedagógica que permita explotar el cómic en las dimensiones léxica, gramática y sociocultural proponemos empezar por una fase de descubrimiento en la que el docente explique o recuerde cómo se lee un cómic, porque la lectura de este género literario en occidente conlleva un código que no todos los estudiantes conocen previamente. De ahí surge también la necesidad de explicar en un primer momento el léxico específico (bocadillo, viñeta, tipo de plano, etc.) tanto en la lengua extranjera como en lengua materna, seguidamente cabe establecer las pautas de lectura (cómo se lee el cómic, cómo se lee una viñeta, etc.) y, por último, resulta interesante dar algunas claves de lectura esbozando los gestos tipificados (una boca abierta o unos ojos muy abiertos simbolizan sorpresa, el pelo erizado o los ojos desorbitados representan terror o enfado, etc.) para describir las emociones y las características psicológicas de los personajes o introduciendo los diferentes tipos de bocadillo (en forma de nube puede ser un pensamiento o un sueño, con picos asimétricos puede transmitir enfado, etc.). Posteriormente, el docente podrá esbozar las diferentes clasificaciones del cómic en función de su género, de su temática

\footnotetext{
8 «Una tarea se define como cualquier acción intencionada que un individuo considera necesaria para conseguir un resultado concreto en cuanto a la resolución de un problema, el cumplimiento de una obligación o la consecución de un objetivo. Esta definición comprendería una amplia serie de acciones, como, por ejemplo, mover un armario, escribir un libro, obtener determinadas condiciones en la negación de un contrato, jugar una partida de cartas, [etc.]» (MCER, 2002, p. 10). 9 «Las actividades de la lengua suponen el ejercicio de la competencia lingüística comunicativa dentro de un ámbito específico a la hora de procesar (en forma de comprensión o de expresión) uno o más textos con el fin de realizar una tarea» (MCER, 2002, p. 9).

«La competencia lingüística comunicativa que tiene el alumno o usuario de la lengua se pone en funcionamiento con la realización de distintas actividades de la lengua que comprenden la comprensión, la expresión, la interacción o la mediación (en concreto, interpretando o traduciendo). Cada uno de estos tipos de actividades se hace posible en relación con los textos en forma oral o escrita, o en ambas» (MCER, 2002, p. 14).
} 
o del público al que va dirigido y se centrará en los aspectos que más le interesen para la tarea que quiera plantear.

La multiplicidad de posibilidades pedagógicas que ofrece el cómic para trabajar la lectura, la comprensión y la interpretación del texto y de la imagen en el aula es muy amplia y fomenta, por ejemplo, el trabajo cooperativo; es decir un tipo de trabajo en grupos en el que se facilite el aprendizaje intergrupal y, por consiguiente, se optimice el proceso de enseñanza-aprendizaje gracias a la interdependencia positiva entre los alumnos. Estamos hablando de una metodología que se basa en la cooperación interpersonal y de ahí que los

«elementos básicos de la cooperación [sean]: la responsabilidad individual (cada alumno es responsable tanto de aprender el material asignado como de ayudar a los otros miembros del grupo a aprenderlo); la interacción personal promotora entre los alumnos (cada alumno promueve el desempeño de otros); las prácticas interpersonales y grupales, y el procesamiento por parte de los alumnos del modo en que funcionó su grupo» (Johnson, Johnson y Holubec, 1999, p. 65).

Desde nuestro punto de vista, esta metodología resulta interesante porque promueve la creación de relaciones interpersonales positiva y crea una cohesión grupal que fomenta un ambiente de trabajo amable. No obstante, y aunque no se trata de la única manera de trabajar el cómic en el aula, invitamos al docente a pensar en ámbitos o temas amplios de interés general para el usuario de la lengua con el objetivo de presentar situaciones atractivas para el grupo-clase concreto.

Para empezar nuestra reflexión, desde un punto de vista de los clásicos en el ámbito del cómic francófono, queríamos poner de relieve Astérix y Obélix ya que no sólo se trata de una de las mejores ventas en Francia ${ }^{10}$ sino que además representa:

«la "check-list" identitaire nationale. Comme les touristes français de l'époque, les deux héros de la bande dessinée franchissent ensuite les frontières, les concepteurs de la série appliquant le même procédé aux Ibères, aux Germains et aux Grands-Bretons. La caricature, douce ou acerbe, n'indique pas cependant l'abandon de la référence identitaire: toujours sous-jacente elle peut revenir sur le mode sérieux, voire offensif, dès lors que la nation semble confrontée à un avenir incertain» (Thiesse, 2001, p. 17).

Los personajes de René Gosciny y Albert Uderzo representan una fuente artístico-literaria que, a través del humor, esboza los pilares del edificio identitario francés. Con ello, se consolidan las bases no sólo para los autóctonos, sino también para todos aquellos extranjeros interesados o atraídos por la cultura francesa. En este sentido, y si nos dirigimos a un público afincado en España, podemos elegir, por ejemplo, Astérix en Hispanie. Las tareas que podemos proponer pueden variar desde analizar la estructura del cómic hasta hacer una lista con los estereotipos sobre España que aparecen e investigar sobre los estereotipos de los franceses en España.

No obstante, también existen publicaciones contemporáneas que suscitan gran interés entre los lectores. En este sentido, presentamos a continuación una muestra de las múltiples posibilidades que encontramos en el mercado para abordar los aspectos léxicos, gramaticales y socioculturales objetivo de las diferentes secuencias pedagógicas. En primer lugar, si nuestro objetivo es plantear una tarea o actividad sobre una situación comunicativa relacionada con la cocina o la alimentación, proponemos utilizar el album $\dot{A}$ boire et à manger (2012), y su traducción al español $A$ comer y a beber (2012). Las actividades que podemos realizar pueden variar en función del público objetivo desde la preparación de un plato de comida hasta la elaboración de un menú pasando por la traducción de una receta o por la comparación de las características gastronómicas existentes entre las recetas presentadas por el suizo Guillaume Long y las recetas cocinadas en casa. Numerosas son, en efecto, las posibilidades existentes para explotar este cómic. Si optamos, por ejemplo, por realizar un menú, por ejemplo, podemos presentar una serie de pasos como: elegir una serie de platos del cómic y explicar la razón por la que los han elegido, leer las recetas seleccionadas para el menú y hacer la lista de la compra,

${ }^{10}$ Véase: Astérix en tête des ventes de livres en France en 2017, www.lexpress.fr 
aprender el contenido léxico y gramatical, comparar la receta en lengua francesa y la traducción española y reflexionar desde un punto de vista léxico-semántico. Una vez elegida la tarea final y delimitados los pasos para conseguirla, es fácil determinar los objetivos de aprendizaje y las actividades que se van a trabajar adecuando la complejidad en función del nivel del grupo-clase.

Seguidamente, presentamos el cómic Joséphine de Pénélope Bagieu, porque se trata de un cómic que, de manera fresca y sencilla, cuenta el día a día de su protagonista: Joséphine, una joven treintañera, soltera y sin hijos, que vive una vida de lo más normal. Este cómic puede inspiraros para realizar tareas y actividades relacionadas con las actividades cotidianas. Si nuestra tarea es ir de compras, podemos, por ejemplo: hacer una lista con el vocabulario de la ropa que aparece en el fragmento del cómic seleccionado, utilizar esta información en una entrevista realizada a otro compañero con el objetivo de saber cuáles son sus gustos en cuestiones de moda, pedir información en una tienda, elaborar un diálogo entre un vendedor y un comprador siguiendo el modelo presentado o incluso ir más allá y describir los modelos de alguno de los eventos de alfombra roja, ya sea actuales o pasados.

Por otra parte, debemos poner de relieve el papel desempeñado por las series animadas en el ámbito francófono. Titeuf ${ }^{11}$, Boule et Bill ${ }^{12}$, Marsupilami ${ }^{13} \mathrm{y}$ Las aventuras de Tintín ${ }^{14}$ son algunos de los ejemplos que han acompañado las meriendas de varias generaciones. Del mismo modo, todos recordaremos a Gérard Depardieu como Obélix o el papel del cantante Philippe Katrerine en Le Petit Spirou de Nicolas Bary estrenado en 2017. En efecto, numerosas son las adaptaciones televisivas o cinematográficas del ámbito del cómic, por ello también invitamos a trabajar en el aula la imagen a través de la comparativa de una escena en la pantalla y en el texto original. Estamos ante un material pedagógico que nos permite reflexionar en clase sobre una serie de especificidades inherentes al componente cultural francés y francófono accesible a nuestro grupo-clase. Resulta especialmente interesante, realizar actividades de reflexiones sobre la interconexión de los diferentes soportes con el objetivo de explorar la intertextualidad, la interculturalidad y la adaptación a la pequeña o gran pantalla de diferentes textos.

Invitamos, pues, a que el aula se convierta en un espacio de trabajo que favorezca y fomente la reflexión, el aprendizaje y la creatividad. Y, en este sentido, compartimos la perspectiva de Ortiz cuando afirma que:

«el cómic es un medio excelente para favorecer la educación en valores; el lenguaje del cómic ayuda a entender mejor la realidad y el entorno cotidiano del niño y la niña, el esquema de lectura de las historias va a permitir a los alumnos y alumnas fijar el esquema de la literalidad y de la lectoescritura, adquiriendo igualmente un sentido de la ordenación espaciotemporal de los documentos; el docente debe promover la actitud crítica: el análisis y la comprensión del lenguaje del cómic, las actitudes de los personajes a través tanto de lo que dicen y de cómo lo dicen, contribuye a algo tan importante como es que el niño y la niña desarrollen una actitud crítica tanto sobre valores como sobre los mismos elementos estéticos que conforman y caracterizan la historieta» (citado en Paré, 2016, pp. 198-199).

Aquí nos hemos limitado a esbozar algunas ideas que son de interés para el docente con el objetivo de despertar el interés y la curiosidad por el uso del cómic como recurso pedagógico. Se trata, en

\footnotetext{
${ }^{11}$ Esta serie es una adaptación televisiva del cómic creado por Zep. Ha sido difundida desde el 4 de abril de 2001, primero por Canal y después por France 3. También ha sido llevada a la gran pantalla en 2011.

12 Basada en el cómic de mismo nombre, se trata de una serie televisiva presentada por primera vez en 2005 y recreada por Philippe Vidal y difundida por France 3 desde 2016.

${ }^{13}$ Se trata de una serie de animación francesa creada a partir del cómic de Franquin y difundida desde el 18 de marzo del 2000 , en un primer momento fue difundida por Canal J.

${ }^{14}$ Es una serie de animación franco-canadiense basada en la serie de cómics creada por el dibujante belga Hergé. Comenzó a transmitirse en 1991 por France 3.
} 
efecto, de pensar en el uso de una multiplicidad de recursos didácticos que ayuden al docente en su labor de fomentar la tolerancia, propiciar un escenario para conocer otras culturas, impulsar la creatividad y, en definitiva, presentar un escenario educativo, motivador y transversal para los usuarios de la lengua.

\section{Conclusión}

Para terminar y a modo de conclusión podemos afirmar que en el presente artículo hemos propuesto una reflexión sobre algunas de las múltiples posibilidades que presenta el cómic como herramienta pedagógica en el marco de prácticas docentes desde el ámbito del FLE. El interés de la enseñanza del Francés como Lengua Extranjera viene motivado tanto por la importancia que esta lengua tiene en el marco de la Unión Europea como por el papel que desempeña desde un punto de vista de habitantes que la hablan. De hecho,

«selon une nouvelle étude de l'Office de statistique Eurostat, [le français] reste la deuxième langue la plus étudiée au collège dans la communauté européenne. [...] Forte de ses 275 millions de locuteurs dans le monde, le français peut se targuer d'accueillies toujours plus de francophones dans ses rangs. En 2015, les élèves du premier cycle de l'enseignement secondaire de l'Union européenne ont conforté cette progression. Parmi les 17 millions d'écoliers, âgés de 11 a 15 ans, qui étudiaient au moins une langue étrangère, cinq millions d'entre eux $(33,8 \%$ apprenaient le français» (Develey, 2017: www.lefigaro.fr).

Además, se trata de una lengua que abre las fronteras lingüísticas y culturales de los más de ochenta países que forman parte de la Francofonía y, por ello, representa una apertura hacia un ámbito educativo intercultural y a un amplio escenario en el ámbito laboral.

Asimismo, con esta reflexión, pretendemos contribuir a la actualización de las prácticas docentes y pedagógicas en la enseñanza de las lenguas extranjeras, por una parte, y, por otra, potenciar el desarrollo intelectual de los usuarios de la lengua. Invitamos, pues, a utilizar una metodología activa que potencie la creación de interacciones en lengua extranjera y fomente la motivación del grupoclase, pues tal y como recuerdan Manuel Fernández y Óscar Díaz:

«el cómic perfecciona la lectura, desarrolla la expresión, las palabras complicadas se retienen mejor, los relatos se entienden más fácilmente, se fija la atención, el alumnado puede adaptar la lectura a su propio ritmo, se enriquece el vocabulario y se mejoran la ortografía, la percepción y la capacidad de síntesis. Esto es así porque el cómic tiene la cualidad de integrar texto e imagen y al existir un componente irónico (los dibujos), el texto aparece contextualizado, por lo que se entiende mejor.» (1990, pp. 8-9).

Presentamos aquí, por consiguiente, la voluntad de transmitir las posibilidades del cómic en el aula. En el aula podemos leer cómics en voz alta, proponer una lectura dramatizada, escribir los diálogos y onomatopeyas en bocadillos, ordenar viñetas según una secuencia narrativa, movilizar las capacidades lingüísticas y comunicativas para presentar la obra, producir un cómic, etc. Todo ello son actividades que ofrecen un contexto pedagógico que pretende no sólo servir de aprendizaje lingüístico, sino también como una manera de despertar la sensibilidad hacia el lenguaje artístico-literario y hacia una realidad sociocultural que nos permite trabajar una multiplicidad de aspectos que van más allá del aula.

\section{Referencias bibliográficas}

Aparici, R. (1992). El cómicy la fotonovela en el aula. Madrid: Ediciones de la Torre.

Arango Johnson, J. A., Gómez Salazar, L. E., \& Gómez Hernández, M. M. (2009). El cómic es cosa seria. El cómic como mediación para la enseñanza en la educación superior. Caso Universidad Nacional, Universidad de Medellín y Universidad Pontífica Bolivariana. Anagramas, 5(14), pp. 13-32.

Astruc, C. \& Girard. J. (1990). Méthode de lecture Boule et Bill. Magnard: col. Scolaire / Universitaire. 
Aulanier, A. (2013). Adaptations en bande dessinée d'œuvres classiques de la littérature de jeunesse: un outil pour l'enseignement au cycle 3. Education. HAL. pp. 1- 70. Recuperado el 31 de enero de 2018, de https://dumas.ccsd.cnrs.fr/dumas-00908780/document

Bagieu, P. (2010). Joséphine. París: Le livre de poche, col. Bulles en poche.

Bagieu, P. (2011). Joséphine 2: Même pas mal. París: Le livre de poche, col. Bulles en poche.

Bagieu, P. (2012). Joséphine 3: Change de camp. París: Le livre de poche, col. Bulles en poche.

Barrero, M. (2002). Los cómics como herramientas pedagógicas en el aula. Conferencia impartida en las Jornadas sobre Narrativa Gráfica en Jerez de la Frontera el 23 de febrero de 2002. Recuperado el 31 de enero de 2018, de https://www.tebeosfera.com/1/Hecho/Festival/Jerez/ConferenciaJerez020223.pdf

Buron-Brun, B. de (2016). El cómic como herramienta pedagógica transfronteriza. In L. Beltrán Almería, R. de Diego, M. Sotelo Vázquez, \& D. Thion Soriano-Mollá (Coords.), Diálogos en la frontera. De la cultura popular a la cultura de masas en la era moderna. (pp. 13-22). Zaragoza: Cometa, Col. Actas.

Casas, N. (2015). Historia y Análisis de los Personajes en el Cómic. Madrid: Bubok Publishing.

Consejo de Europa (2002). Marco común europeo de referencia para las lenguas. (1 $1^{\mathrm{a}}$ ed.). Madrid: Anaya.

Consejo de Europa (2018). Cadre européen commun de référence pour les langues : apprendre, enseigner, évaluer. Volume complémentaire avec de nouveaux descripteurs. Recuperado el 22 de marzo de 2019 de https://rm.coe.int/cecr-volume-complementaire-avec-de-nouveaux-descripteurs $/ 16807875 \mathrm{~d} 5$

Develey, A. (2017). Le français est la deuxième langue la plus étudiée dans l'Union européenne. En Le Figaro, 25 de febrero de 2017. Recuperado el 31 de enero de 2018, de http:/ /www.lefigaro.fr/langue-francaise/actu-des-mots/2017/02/25/37002-20170225ARTFIG00101-lefrancais-est-la-deuxieme-langue-la-plus-etudiee-dans-l-union-europeenne.php

Eisner, W. (1996). El cómic y el arte secuencial. Teoría y práctica de la forma de arte más popular del mundo. Barcelona: Norma.

Fermández, M. \& Díaz, O. (1990). El cómic en el aula. Madrid: Alhambra Longman.

Goscinny, R. \& Uderzo, A. (2005). Astérix en Hispanie, n¹4. Paris: Hachette.

Long, G. (2012). À boire et à manger. Paris: Gallimard.

Long, G. (2012). A comery a beber. Madrid: Salamandra Graphic.

Long, G. (2012). À boire et à manger. Les pieds dans le plat. Paris: Gallimard.

Long, G. (2014). A comery a beber. Con las manos en la masa. Madrid: Salamandra Graphic.

López Socassau, F. (1998). Diccionario Básico del Cómic. Madrid: Acento Editorial.

Lungheretti, P. (2017). La bande dessinée connaît en France un nouvel âge d'or", pas ses auteurs. Le Monde, 25 de octubre de 2017. Recuperado el 31 de enero de 2018, de https://www.lemonde.fr/idees/article/2017/10/25/la-bande-dessinee-connait-en-france-un-nouvel-age-dor-pas-ses-auteurs_5205909_3232.html 
Gómez Salamanca, D. (2013). Tebeo, cómic y novela gráfica: La influencia de la novela gráfica en la industria del cómic en España. (Tesis Doctoral). Universidad Ramón Llul, Barcelona.

Johnson, D. W., Johnson R. T., \& Holubec, E. J. (1999). El aprendiraje cooperative en el aula. Buenos Aires: Paidós.

McCloud, S. (2005). Entender el cómic. Bilbao: Astiberri Ensayo.

Ministerio de Educación, Cultura y Deporte (2018). Barómetro de Hábitos de Lectura y Compra de Libros 2017. Recuperado el 31 de enero de 2018, de https://fomentodelalectura.culturaydeporte.gob.es/actualidad/noticias/Bar-metro-2017.html

Missiou, M. (2012). Un médium à la croisée des théories éducatives: bande dessinée et enjeux d'enseignement. In N. Rouvière (Dir.): Bande dessinée et enseignement des humanités. Grenoble: ELLUG, Collection Didaskein, pp. 79-98.

Ortiz, J. (2009). El cómic como recurso didáctico en la Educación Primaria. Temas para la Educación, Revista digital para profesionales de la educación, 72(5), pp. 1-6.

Paré, C. (2016). Diseño, aplicación y evaluación de un modelo didáctico basado en el cómic francófono para el aula de francés, lengua extranjera de Educación Primaria. (Tesis Doctoral). Universidad de Murcia, Murcia.

Paré, C. \& Soto Pallarés, C. (2017). Análisis descriptivo del uso del cómic en los libros de texto de francés lengua extranjera. Education Siglo XXI, 35(2), pp. 134-143.

Peña Acuña, B. (Coord.) (2014). Vectores de la pedagogía docente actual. Madrid: ACCI.

Prado Aragonés, J. (1995). Aprender a narrar con el cómic. Comunicar, (5), pp. 73-79.

Rollán Méndez, M. \& Sastre Zarzuela, E. (1986). El cómic en la escuela. Aplicaciones didácticas. Valladolid: Universidad de Valladolid.

Thiesse, A-M. (2001). La création des identités nationales. Paris: Point Histoire.

Toledano, B. (2018). Móviles listos, móviles tontos... y otras cinco lecciones del Mobile World Congress. El Mundo, 27 de febrero de 2018. Recuperado el 31 de enero de 2018, de https://www.elmundo.es/papel/futuro/2018/02/27/5a94664fe5fdea0a5f8b462f.html 